\title{
UM PANORAMA HISTÓRICO DA POLÍTICA DE FORMAÇÃO DE PROFESSORES NO BRASIL
}

\author{
A Historical Overview Of Teacher Education Policy In Brazil
}

\section{Una Visión Histórica de la Política de Formación del Profesorado en Brasil}

\author{
Alexandre Macedo Pereira ${ }^{1}$ \\ Luis Fernando Minasi ${ }^{2}$
}

Resumo: Do Império (século 19) até a República atual (século 21), a formação de professores no Brasil experimenta fracassos sucessivos. Alternam-se as elites políticas e econômicas no poder, os programas macro-econômicos, mas os problemas na educação brasileira se repetem. A formação de professores está cada vez mais nas mãos da iniciativa privada e, as universidades públicas têm se rendido as exigências e interesses do mercado, "produzindo" assim, em série, professores medíocres. Este trabalho tem como objetivo apresentar as contradições e as consequências da política de formação de professores no Brasil. Esta é uma pesquisa exploratória de caráter bibliográfico.

Palavras-chave: Formação de professores. Educação. Política pública de educação.

\section{INTRODUÇÃO}

De 1996 até hoje, inúmeras são as polêmicas que envolvem a discussão sobre a política de formação de professores no Brasil. Ao longo destes 17 anos, muitas são as antinomias não resolvidas. Grandes são as frustrações dos docentes, discentes e da sociedade com os resultados pífios dos "investimentos" do Estado na formação de professores neste país. Problemas como precarização do trabalho docente, baixo investimento financeiro no sistema educacional etc., além das pressões políticas internas e externas, compromissos econômicos com sistema financeiro nacional e internacional compõem o cenário complexo da formação de professores no Brasil.

Em meio a tantas contradições históricas, o Estado insiste em desenvolver política pública de formação de professores, de caráter expansionista (com clara preocupação com os aspectos estatísticos), a partir dos pressupostos do mercado, focado na formação de mão de obra, em "parceria" com a iniciativa privada (por meio incentivos fiscais, programas de

\footnotetext{
${ }^{1}$ Doutorando em Educação Ambiental no Programa de Pós-Graduação em Educação Ambiental - PPGEA na Universidade Federal do Rio Grande - FURG e Bolsista Capes. E-mail: c.cpa2008@ hotmail.com.

2 Doutor em educação pela Universidade Federal do Rio Grande do Sul. Professor da Universidade Federal do Rio Grande - FURG e do Programa de Pós-Graduação em Educação Ambiental - PPGEA. E-mail: lfminasi@terra.com.br.
} 
concessão de bolsas de estudos etc.). A política de expansão da formação de professores, fundamentada nos interesses ideológicos e político dos setores econômicos e financeiros, tem inviabilizado a construção de um projeto de formação de professores que tenha como centralidade a omnilateralidade.

O presente artigo tem como objetivo discutir as diretrizes gerais da política de formação de professores no Brasil, e analisar as contradições, limites e possibilidades da mesma.

A pesquisa em questão tem como pressuposto teórico-metodológico o materialismo histórico-dialético, e foi realizada a partir da análise de documentos do MEC, INEP, entre outros.

O artigo está organizado em cinco seções: caminhos da formação de professores no Brasil, o perfil da formação de professores no Brasil, a Capes e a "nova" formação de professores e considerações finais.

\section{CAMINHOS DA FORMAÇÃO DE PROFESSORES NO BRASIL}

Faremos nesta seção o percurso histórico da formação de professores no Brasil, tendo como referencial temporal inicial, a Lei de Diretrizes e Bases da Educação Nacional (Lei 9.394/96), aprovada e implementada no governo de Fernando Henrique Cardoso (1995-2002). Escolhemos partir do ano de 1996, por ser este momento um marco na "nova" organização social e política no país. Nesse momento, o país, sob o governo do PSDB, adota a política neoliberal, que tem como foco central a privatização de instituições públicas, flexibilização das leis trabalhistas e desregulamentação do mercado financeiro, sustentada no discurso do "Estado mínimo".

Apresentaremos através do desenvolvimento da história, os caminhos e descaminhos da política de formação de professores, direcionando a atenção para o passado sem tirar o foco do presente, pois sabemos que não é no passado isolado que se encontra a chave da compreensão do presente mas, é mirando o presente que podemos compreender o passado, entendendo que é na história que as categorias, “determinações da existência, as formas do ser", em seu desenvolvimento, nos possibilita conceber cada ente (LUKACS, 2010, p. 70). No entanto, a história não é apenas um saber, é sim, a elucidação da práxis enquanto passado, ou

\footnotetext{
Revista de Ciências Humanas | FW | v. 15 | n. 24 | p. 7-19 | Jul. 2014

Recebido em: 19 mar. 2014

Aceito em: 28 jul. 2014
} 
como nos adverte o filósofo húngaro: “[...] forças motoras do passado que, ao dar expressão plástica à relação presente dos seres humanos com a sua própria generalidade, podem ser mais eficazes que os simples fatos do presente" (LUKACS, 2010, p. 110).

Portanto, embora o nosso marco temporal seja 1996, iniciaremos a nossa jornada (ainda que breve) a partir dos anos 30 do século XIX. Este retorno nos permitirá compreender a complexidade e natureza da formação de professores, além de indicar alguns elementos que a fizeram fracassar.

Em 1835 foram criadas as primeiras escolas normais nas províncias, cuja função central era cuidar da formação de professores, com o objetivo de "capacitá-los" para a condução do ensino primário no Império. Era uma escola aristocrática de caráter conservador, cujo objetivo era manter o controle das classes populares.

Todavia, a política de formação de professores, instituída no século XIX, naufragou em razão da falta de investimentos em pessoal, infra-estrutura, desvalorização da profissão do magistério, e incapacidade do Estado em expandir a escola normal etc. Segundo o ministro João Alfredo, o sistema de ensino era deficiente, os professores eram mal remunerados e insuficientes às escolas, o ensino pedagógico era nulo e imperfeito à fiscalização (MOACYR, 1937, p. 139).

É no início do século XX que o Estado brasileiro manifesta formalmente interesse na formação de professores para o ensino secundário (hoje anos finais do ensino fundamental e o médio), com a instituição de cursos regulares específicos. Anterior a este período, a docência era exercida por profissionais liberais ou autodidatas, não havendo, por parte do Estado, políticas ou leis que regulamentassem a formação de professores.

Somente no final dos anos de 1930, o Estado instituiu a regulamentação da formação de professores, determinando uma nova composição na formação. Nessa nova formatação, os bacharéis que lecionavam, ao fazerem mais um ano de curso, com disciplinas de educação, obtinham também o grau de licenciado.

O processo estava direcionado à formação de professores do secundário (denominada popularmente de $3+1$ ). Este é o modelo que o curso de pedagogia criado em 1939, vai adotar para a formação de bacharéis especialistas em educação, e assim, formar professores para as escolas normais (GATTI; BARRETTO; ANDRÉ, 2011, p. 97).

\footnotetext{
Revista de Ciências Humanas | FW | v. 15 | n. 24 | p. 7-19 | Jul. 2014

Recebido em: 19 mar. 2014

Aceito em: 28 jul. 2014
} 
Em 1986, o Conselho Federal de Educação, por meio do parecer n ${ }^{\circ}$ 161/1986 reformula o curso de pedagogia, e estabelece a formação de professores de $1^{\mathrm{a}}$ a $4^{\mathrm{a}}$ séries do ensino fundamental. Vale destacar que, mesmo sem esta regulamentação, algumas instituições já o faziam com autorização provisória do MEC.

É interessante observar que o Parecer 161/1986 tem impacto direto nas instituições superiores privadas, fazendo-as se adaptarem para atender a normativa. No entanto, a maioria das instituições públicas, que ofertavam o curso de pedagogia, continuou formando bacharéis, no modelo originário do curso, com a complementação para licenciatura. Cabe ressaltar que ainda vigoravam os currículos mínimos obrigatórios determinados pelo Conselho Federal de Educação (CFC).

Pressionado pela política externa dos Estados Unidos e Inglaterra e organismos internacionais como o Banco Mundial, ONU/UNESCO etc., entre os anos 1980 e início dos 1990, e, pelas necessidades de mudanças internas, o Brasil, governado pelo então presidente Fernando Henrique Cardoso (FHC), institui a Lei 9.394/96 que estabelece a Lei de Diretrizes e Bases da Educação Nacional (LDBEN), com o objetivo de formar os professores agora em nível superior em um prazo de dez anos.

A LDBEN introduz nova estrutura formativa para professores da educação básica, de modo integrado e sob a responsabilidade dos Institutos Superiores de Educação, realizadas no âmbito do espaço e estrutura das instituições de ensino superior.

A resolução 1/2002 do Conselho Nacional de Educação (CNE) estabeleceu que a formação de professores estivesse estruturada sob uma base comum curricular. Segundo Gatti, Barretto e André (2011, p. 95), tais disposições legais não obtiveram êxito e nem alteraram a realidade da educação no país. A falta de êxito se deve à capacidade de influência de grupos interessados na não alteração do processo, como também pela falta de vontade política; ou a falta de poder político das instâncias federais reguladoras e gestoras da formação em nível superior. Todavia, as disputas que impediram a efetivação das determinações legais foram travadas em dois âmbitos distintos: o público e o privado (GATTI; BARRETTO; ANDRÉ, 2011, p. 95).

As determinações da LDBEN e da Resolução 1/2002 acabaram criando circunstâncias que não favoreciam as determinações de mercado, a que estavam submetidas as instituições privadas. Sob a ótica do mercado - ênfase essencialmente no lucro - as instituições

Revista de Ciências Humanas | FW | v. 15 | n. 24 | p. 7-19 | Jul. 2014

Recebido em: 19 mar. 2014

Aceito em: 28 jul. 2014 
educacionais superiores privadas travaram um disputa política para que as determinações legais fossem revogadas e houvesse diminuição do tempo de duração das licenciaturas (GATTI; BARRETTO; ANDRÉ, 2011, p. 96). Esta postulação da iniciativa privada, após anos de disputas, alcançou seus objetivos: inviabilizou a aplicação da integração curricular das licenciaturas e diminuiu o tempo de duração destas.

As disputas também ocorriam nas instituições educacionais superiores públicas. Tais disputas estavam ancoradas em embates políticos ideológicos entre grupos partidários divergentes relacionados às Associações que representam as instituições públicas, e, na estrutura político-administrativa das universidades públicas. Portanto, a reconfiguração proposta pela Resolução 1/2002 também implicou em transformações estruturais nas universidades públicas, tais como: reestruturação de departamentos, redistribuição de cargos e carga horária dos docentes. Estas alterações necessárias, de acordo ao que previa a resolução 1/2002, atingiam área de interesse e de disputas internas nas instituições públicas (GATTI; BARRETTO; ANDRÉ, 2011, p. 96).

Todavia, o reconhecimento em si da crise na formação de professores, desconexo das relações de causas e efeitos próprios do modo de produção capitalista produz propostas socialmente inviáveis e reformistas, mantendo-se assim, na esfera do conservadorismo (LESSA, 2012, p. 37). Em uma sociedade cujas relações são de expropriação e exploração, a educação tem por função reproduzir relações de exclusão e expropriação. O valor do homem neste modelo de sociedade se resume a força de trabalho.

Segundo Tonet (2012, p. 16): [...] "a função hegemônica da educação é a de preparar os indivíduos para se inserirem no mercado de trabalho. Pois, nesta formação de sociabilidade, o indivíduo vale enquanto força de trabalho e não enquanto ser humano integral". Portanto, analisar formação de professores sem considerar a contradição existente entre o discurso e a prática social educativa é, em nosso entender, negar a legalidade ontológica da educação/formação de professores/ escola nesta sociabilidade. Assim sendo, nesse modelo de organização social, a educação cumpre a função de reprodução social do capital (TONET, 2012, p. 17).

Cabe também ressaltar, que embora as autoras evidenciem a distinção de interesses, entre as instituições superiores privadas e públicas, ambas, dentro desta organização social, estão sincronizadas com a reprodução do capital e preparação de mão de obra para o mercado.

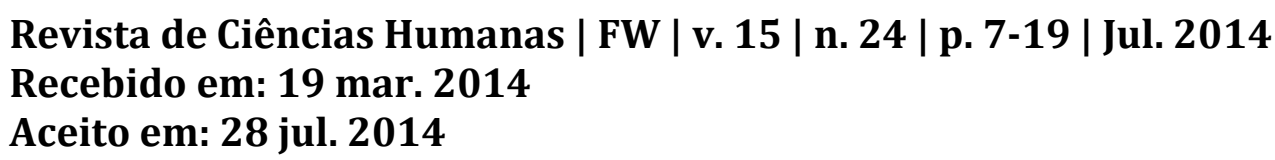


Por isso, para Tonet (2012, p. 14), [...] "a função essencial da educação é preparar os indivíduos para o trabalho". Nunca é demais reforçar que este trabalho é alienado e estranho ao próprio homem e o subjuga. Neste sentido Marx (2009, p. 89) afirma que o trabalho (abstrato) se torna insuportável ao homem.

Embora as disputas fizessem parte desse processo, as alterações propostas pela LDB deveriam alcançar as instituições formadoras e os cursos de formação de professores. Para isso, foi estabelecido um período de transição para sua efetivação. Com a Resolução CNE/CP $n^{\circ}$ 1/2002 são promulgadas as Diretrizes Curriculares Nacionais para Formação de Professores, e, subsequentemente, nos anos seguintes, as Diretrizes Curriculares para cada curso de licenciatura foram aprovadas pelo CNE. Embora, no início do século XXI tenha havido por parte do Estado, esforço para alterar a qualidade da formação de professores no país, o que se verifica é a predominância do modelo consolidado no século anterior (GATTI; BARRETTO; ANDRÉ, 2011,p. 98).

É importante evidenciar que mesmo com todas as mudanças propostas e efetivadas pelo MEC, o curso de pedagogia só foi alterado no ano de 2006, após acalorados debates. A partir da Resolução CNE/CP n ${ }^{\circ}$ 1/2006, foi estabelecida as Diretrizes Curriculares Nacionais - DCN, para os cursos de pedagogia, alterando sua configuração de bacharelado para licenciatura. Com esta nova forma, passou a ser responsabilidade da pedagogia, a formação de professores para educação infantil e anos iniciais do ensino fundamental, ensino médio na modalidade normal e, em casos específicos, educação de jovens e adultos e formação de gestores, além de possibilitar aptidões previstas no artigo $5^{\mathrm{a}}$ da referida Resolução e, por fim, realizar estágio curricular, conforme o inciso IV, artigo $8^{\mathrm{a}}$. Notadamente a licenciatura em pedagogia assume amplas atribuições, sendo o foco central a formação de professores para os anos iniciais da escolarização (GATTI; BARRETTO; ANDRÉ, 2011, p. 98).

Esta amplitude de atribuições se constitui em um problema para o curso, uma vez que, a formatação do currículo é complexa, acarretando na dispersão disciplinar em razão do tempo de duração do curso e sua carga horária, associado à formação de habilidades de planejamento, execução, coordenação, acompanhamento e avaliação de atividades inerentes ao processo educativo, projetos e experiências educacionais não escolares, produção e difusão do conhecimento científico-tecnológico do campo educacional, no âmbito da escola e fora dela, torna o curso de pedagogia genérico, fragmentado e frágil. Ressaltamos, todavia, que a

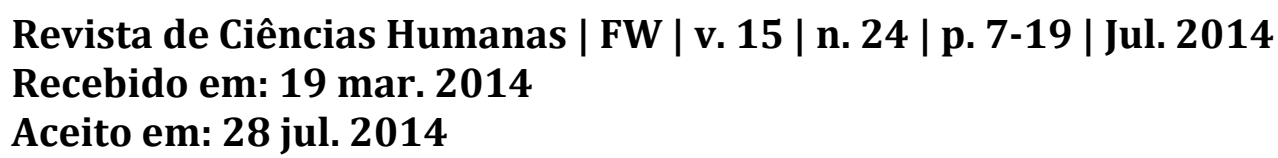


superação de tais problemas não representa a superação da legalidade ontológica dessa formação/educação/escola, como já afirmamos acima.

Um ponto a ser destacado nesse processo, é a regulamentação do MEC sobre os cursos ofertados pela Educação a Distância (EaD) a partir de 1998. Nesse período, o MEC estabelece as condições para o credenciamento de instituições e as autorizações de cursos à distância, objetivando fortalecer e ratificar a "importância" da EaD, além de fazer "correções" às distorções percebidas durante o processo de funcionamento até aquele momento.

Em 2001, foi sancionado pela Lei 10.172, o Plano Nacional de Educação, o qual reafirmava a relevância da $\mathrm{EaD}$ nas políticas de educação e determinava as diretrizes, os objetivos e metas para sua implantação. Mediante o desafio de atender a demanda criada na área, o Plano Nacional de Educação determinou a ampliação da oferta de cursos de formação de professores com nível superior na modalidade a distância e aporte financeiro à pesquisa sobre a $\mathrm{EaD}$.

No mesmo ano, o MEC baixou a Portaria $n^{\circ} 2.253$, autorizando as Instituições de Ensino Superior a introduzirem na estrutura curricular dos cursos presenciais, disciplinas não presenciais, condicionando as mesmas instituições a um limite de no máximo $20 \%$ da carga horária total do curso, e, que as avaliações finais deveriam ser presenciais. Em 2004, pela Portaria $n^{\circ} 4.059$, o MEC revoga a Portaria $n^{\circ} 2.253 / 2001$, estabelecendo que as disciplinas dos cursos presenciais, ofertadas na modalidade não presencial, passariam a ser semipresencial, exigindo dos cursos uma estruturação pedagógica e curricular que contemplasse os encontros presenciais e atividades de tutoria. Nesta Portaria fica estabelecido que a tutoria deve ser exercida por docentes com formação diretamente relacionada ao projeto pedagógico do curso, além de carga horária específica para os momentos presenciais e à distância.

As experiências acumuladas com a EaD até o ano de 2004, associado à necessidade de resolver as distorções existentes no sistema público de educação brasileiro - o alto índice de professores atuando na educação pública, sobretudo no ensino fundamental, sem nenhuma formação superior ou formação superior compatível a área de atuação, além das pressões internacionais, exigências do mercado etc., forçam o governo em 2005 a estabelecer uma nova regulamentação para $\mathrm{EaD}$, através do Decreto $\mathrm{n}^{\circ}$ 5.622. Este estabelece que cursos e programas a distância ao serem projetados, sigam as mesmas determinações quanto a carga

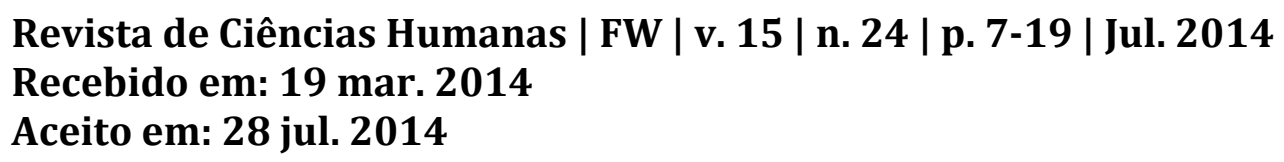


horária, dos cursos presenciais, pois a partir do referido Decreto, fica estabelecido a equivalência de certificados e diplomas aos cursos presenciais. Em tese, as regras para o credenciamento dos cursos da $\mathrm{EaD}$ endurecem, tendo como foco a elevação da qualidade dos mesmos (GATTI; BARRETTO; ANDRÉ, 2011, p. 100).

Ora, o que nos parece estranho nestas "novas" determinações do MEC, é que os parâmetros utilizados para "reorganizar" a EaD são extraídos dos cursos presenciais, como se os mesmos não estivessem mergulhados em um crise profunda. O MEC adota políticas de expansão da formação de professores sem ter criado as condições materiais necessárias para elevação da qualidade dos cursos presenciais.

Segundo Gatti, Barretto e André (2011, p. 100), em 2007, por meio de Decreto 6.303, o MEC altera dispositivos do Decreto ${ }^{\circ} 5.622 / 2005$, e:

\footnotetext{
define melhor os quesitos ligados à abrangência da atuação das IESs para a modalidade da EaD, as atividades obrigatórias [...]. Além disso, é detalhado aspectos referentes ao credenciamento institucional, recredenciamento, autorização e reconhecimentos de cursos. Atribui a Capes editar normas complementares a esse Decreto, no que se refere à pós-graduação stricto sensu.
}

As alterações na política de formação de professores consistem em determinar a abrangência da atuação e, transferência de responsabilidades de uma entidade a outra, ou seja, são todas mudanças no âmbito burocrático administrativo, que efetivamente não estão ligados aos problemas centrais do processo de formação de professores. Uma clara evidencia do distanciamento do Estado em relação às demandas concretas da sociedade. Por isso, nem no plano imediato, na dimensão das exigências históricas como se apresentam, observamos efetividade das políticas públicas no que diz respeito ao processo de formação de professores.

Portanto, a afirmação da Gatti, Barretto e André (2011, p. 100-101) quanto à consistência da regulamentação da $\mathrm{EaD}$, bem como, dos problemas estarem focados no processo de credenciamento, acompanhamento e avaliação dos cursos, na nossa compreensão, é superficial e consequentemente frágil. A primeira fragilidade, em nosso entendimento, é afirmar que a regulamentação da $\mathrm{EaD}$ está bem posta.

Parece-nos incoerente afirmar que tal regulamentação está consolidada, uma vez que, a mesma vem sendo contestada entre os próprios professores formadores. Apenas para dar exemplo, na greve dos professores das universidades federais em 2012, foi estabelecido um amplo debate sobre a prática de formação de professores nas universidades públicas federais Revista de Ciências Humanas | FW | v. 15 | n. 24 | p. 7-19 | Jul. 2014 Recebido em: 19 mar. 2014 Aceito em: 28 jul. 2014 
no Brasil, e no centro deste debate aparece uma contestação aberta e intensa ao PARFOR, REUNI etc. Se as autoras falam em nome do Estado, o discurso de consolidação pode caber, porém, não significa que assim o seja na realidade. Entendemos que não pode estar consolidado o que é alvo de constantes críticas e que não foi amplamente debatido com a sociedade.

A Segunda fragilidade centra-se na limitação do problema. Para as autoras o problema reside "tanto no credenciamento quanto no acompanhamento e na avaliação desses cursos por parte do poder público" (GATTI, BARRETTO E ANDRÉ, 2011, p. 100-101). Da forma como está posto o discurso, podemos concluir que a questão se resolveria efetivamente pela manutenção da política de vigilância, punição e controle sobre o processo. A questão é: se não houve ou não há controle, a quem interessa? E a quem interessa esse controle agora?

\section{O PERFIL DA FORMAÇÃO DE PROFESSORES NO BRASIL NA ATUALIDADE}

Nesta seção apresentaremos, através de dados extraídos do Resumo Técnico do Censo da Educação Superior do MEC/INEP (2011), informações sobre a educação superior no Brasil, com objetivo de traçar características da formação de professores destacando determinadas dinâmicas do processo.

A primeira informação ser destacada é quanto à disposição das matrículas. Consideramos tais dados relevantes, por demonstrarem que a política de expansão dos cursos superiores está ancorada na expansão das vagas em instituições privadas. De acordo com o MEC/INEP em 2011, 72,2\% das matriculas presenciais nos cursos superiores no Brasil são realizadas nas instituições de ensino privadas e apenas $27,8 \%$ em instituições públicas. No caso particular da região norte, $56,3 \%$ das matrículas presenciais está na rede privada e 43,7\% na iniciativa pública. Dos 29.376 cursos presenciais, 20.009 estavam na instituição privada e na rede pública apenas 9.368 .

Quando considerado a soma dos cursos presenciais e a distância, em 2011 havia no Brasil, 30.420 cursos de graduação declarados no censo, sendo que 17.031 bacharelados (56\%), 7.911 licenciaturas (26\%) e 5.478 tecnológicos (18\%). Neste mesmo ano, as matrículas chegaram a 6.739.689, sendo que 4.495.831 destas matrículas estavam nos cursos

\footnotetext{
Revista de Ciências Humanas | FW | v. 15 | n. 24 | p. 7-19 | Jul. 2014

Recebido em: 19 mar. 2014

Aceito em: 28 jul. 2014
} 
de bacharelado (66,7\%), 1.356 .329 cursos de licenciatura $(20,1 \%), 870.534$ cursos tecnológicos $(12,9 \%)$ e 16.995 não se aplica $(0,3 \%)$.

Quanto à modalidade, os cursos presenciais concentravam 4.196.423 de matrículas nos cursos de bacharelados (73\%), 926.780 das matriculas nos cursos de licenciatura $(16,1 \%)$ e 606.564 das matriculas nos cursos tecnológicos. Na modalidade à distância, 429.549 matrículas foram registradas nos cursos de licenciaturas (43,3\%), 299.408 no bacharelado $(30,2 \%)$ e, 263.970 em cursos tecnológicos $(26,6 \%)$.

No que diz respeito ao processo de participação das instituições educacionais de nível superior pública e privada quanto à distribuição das matrículas em cursos na modalidade presencial e a distância, em 2011, 1.772.315 destas (26,3\%) foram registradas nas instituições públicas e, 4.966 .374 nas instituições privadas $(73.7 \%)$.

Os indicadores revelam a face cruel e cínica das políticas públicas de acesso a formação superior implementadas pelo Estado e governos. São políticas nacionais comprometidas com políticas internacionais decididas por nações ricas e exploradoras, que tem por objetivo proteger o capital. O que vemos acontecer no Brasil é uma nova forma de privatização do ensino superior. Se nos 1990, o governo FHC, promoveu o sucateamento das universidades federais com o objetivo de "vendê-las" para iniciativa privada (privatização clássica), temos vivenciado no governo do "Partido dos Trabalhadores" o fortalecimento das instituições de ensino superior privadas; esta política está sustentada em financiamento, seja pela isenção fiscal, oferta de bolsas de estudos total ou parcial, reembolsáveis ou não, ou através de linhas de créditos baratos, financiados com dinheiro público, utilizando para este fim instituições financeiras, Banco do Brasil, Caixa Econômica Federal, Banco Nacional de Desenvolvimento, entre outros mecanismos e instituições.

Para Gatti, Barretto e André (2011, p. 105):

O grande número de matrículas em cursos de $\mathrm{EaD}$ em instituições privadas está em consonância com a oferta que fazem nessa modalidade, deixando de oferecer cursos de licenciatura presenciais, sobretudo os de pedagogia. Esse movimento, que é grande e rápido, precisa ser olhado com cautela, uma vez que há questionamentos quanto à qualidade na oferta desses cursos e os materiais utilizados. Não é uma política sensata estimular a expansão desses cursos, ante as avaliações e as dúvidas levantadas por pesquisadores. Transformar, como os dados mostram, especialmente a formação de professores para educação básica majoritariamente em formatos a distância pode trazer conseqüências para qualidade das ações pedagógicas a serem desenvolvidas com crianças e adolescentes nas escolas de educação básica.

\author{
Revista de Ciências Humanas | FW | v. 15 | n. 24 | p. 7-19 | Jul. 2014 \\ Recebido em: 19 mar. 2014 \\ Aceito em: 28 jul. 2014
}


É interessante notar que a crítica das autoras centra-se no pressuposto da qualidade dos cursos sem, contudo, explicitar o parâmetro de qualidade que elas utilizam por referência, e, em nosso entender, particularizando a crítica, fragmenta-se a análise. Seria oportuno incluir neste debate a qualidade dos cursos presenciais, a precarização do trabalho docente (professores e tutores), a atribuição da responsabilidade de formar professores para a rede pública de educação e, a relação capital e Estado. Parece-nos interessante destacar que as análises sobre a política de formação de professores, acesso e qualidade dos cursos, ainda insistem em olhar para a superficialidade do fenômeno, negando assim, a possibilidade de conhecê-lo, dado as condições materiais, no seu movimento, na sua totalidade, a sua essência.

Fica evidente que no modelo político atual, a universidade pública ocupa um papel secundário no processo de formação de professores, bem como na formação geral dos jovens e adultos que ingressam na universidade. No ano de 2012, 73,7\% das matrículas nos cursos superiores estavam concentradas na iniciativa privada, sendo que os cursos com maior presença na modalidade presencial foi o bacharelado, enquanto as licenciaturas foram mais representativas nos cursos na modalidade à distância.

Segundo Resumo Técnico do Censo da Educação Superior do MEC/INEP (2010):

\begin{abstract}
A maioria desses cursos-licenciaturas e "bacharelado + licenciatura" (64\%) está em universidades públicas ou privadas e, quanto ao número de matriculados, a maior parte está nas instituições privadas: 68\% das matrículas em licenciaturas de pedagogia e 53\% das matrículas nas demais licenciaturas. Outro dado a destacar é que, enquanto $71 \%$ dos cursos de bacharelado são presenciais, $50 \%$ dos cursos de licenciatura são ofertados na modalidade a distância. Entre os dez maiores cursos de graduação em termos de matrículas, o curso de pedagogia, que forma docentes para os primeiros anos do ensino fundamental, situa-se em $3^{\circ}$ lugar, com 9,6\% das matrículas. Esse mesmo curso está em $1^{\circ}$ lugar, quanto ao número de matrículas na $\mathrm{EaD}$, com $34,2 \%$ do total de matrículas nessa modalidade (BRASIL. MEC. INEP, 2010b, p. 13,14,19).
\end{abstract}

Quanto ao processo de distribuição das matrículas nos cursos de graduação presencial no espaço geográfico, levando-se em consideração que o MEC/INEP adota como critério de localização geográfica uma distinção ampla, capital e interior, e a atuação de instituições públicas e privadas nesses espaços, podemos constatar que: dos 5.746 .762 de matrículas, 2.713.589 estão na capital $(47,2 \%)$ e 3.033 .173 (52,8\%) no interior. Segundo o MEC/INEP, os dados referentes à rede pública, em 2011, estão assim distribuídos: as instituições federais possuíam 927.086, sendo que destas, 498.528 na capital $(53,8 \%)$ e 428.566 no interior

\author{
Revista de Ciências Humanas | FW | v. 15 | n. 24 | p. 7-19 | Jul. 2014 \\ Recebido em: 19 mar. 2014 \\ Aceito em: 28 jul. 2014
}


(46,2\%); as instituições estaduais registraram 548.202 matrículas, sendo 156.703 na capital $(28,6 \%)$ e, 391.499 no interior $(71,4 \%)$ e, as instituições municipais tinham o contingente de matrículas de 120.103, todas no interior. Quanto a rede privada, as matrículas em 2011 foram 4.151.371, sendo 2.058.366 na capital $(49,6 \%)$ e, 2.093 .005 no interior $(50,4 \%)$.

Os dados apresentados devem ser analisados com atenção, pois, os mesmos se não observados em um contexto macro podem nos induzir a erros de conclusão. Se apressados formos ao analisar estes dados, podemos incorrer no equívoco de afirmar que estamos diante de um processo equânime, equilibrado e democrático de expansão das instituições de ensino superior pelo território brasileiro.

Os dados demonstram que aparentemente há um equilíbrio na distribuição geográfica dessas instituições, parecendo ser balanceada a distribuição das instituições públicas federais e estaduais entre as capitais e o interior. Porém, os dados são amplos, o que impossibilita compreender o fenômeno. Da forma como está posto a realidade fica maquiada, ou seja, a realidade cruel é que a maioria dos municípios do país não têm instituições superiores de ensino, comprometendo assim, o acesso das pessoas ao ensino superior público.

Por isso, afirmamos que este critério não serve para analisar a realidade. A democratização do ensino superior no país é e sempre foi apenas um discurso falso, ideologicamente destinado à manutenção do controle dos excluídos e da classe trabalhadora. Fazemos esta afirmação considerando, entre outros fatores, o fato que dos 5.570 municípios, apenas 2.053 têm a presença de alguma instituição de nível superior na modalidade presencial e/ou à distância. Se considerarmos que deste universo de municípios atendidos por instituições superiores, um elevado número é atendido por instituições privadas e que ofertam cursos na modalidade à distância, podemos afirmar ser esta situação um indício sério do processo de fortalecimento da exclusão das pessoas ao acesso à educação superior, sobretudo pública e gratuita.

Quanto ao acesso e à qualidade, existe exclusão. Nos fundamentamos nas condições econômicas de existência de parcela significativa da população brasileira. Usamos como categorias de referência para sustentar esta tese, os indicadores sociais bolsa família e o índice de desemprego no país. No que se refere a bolsa família, 13,6 milhões de famílias vivem com este auxílio (70 reais), e, segundo o jornal Estadão, em 2012 o Brasil teve 6.58 milhões de pessoas desempregadas (6.3\%), que segundo a Organização Mundial do Trabalho, em 2013

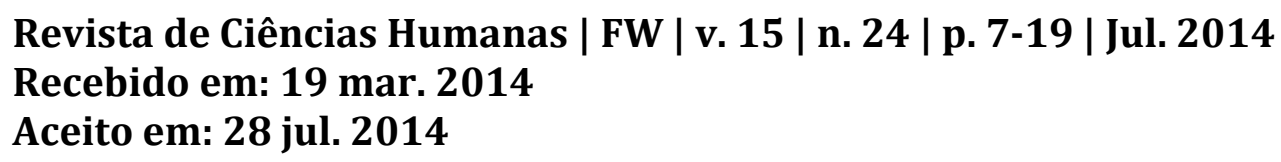


este número chegará a 6.89 milhões (6.5\%) e em 2014 a 7.08 milhões de desempregados (6.6\%). Nessas condições financeiras e sociais é impossível a população ter acesso a formação superior no Brasil, se este continuar adotando a política de acesso a partir da expansão das instituições privadas.

Vale ressaltar que não estamos aqui destacando elementos como baixo salário, precarização do trabalho, falta de estrutura das instituições públicas de ensino superior para atender as necessidades reais da classe trabalhadora que adentra ao ensino superior.

\section{A CAPES E A "NOVA" FORMAÇÃO DE PROFESSORES}

Com a reformulação do sistema, a Capes passou a ter uma função estratégica no processo de formação de professores. Através da Lei $\mathrm{n}^{\circ} 11.502 / 2007$ e do Decreto $\mathrm{n}^{\circ}$ 6.316/2007, a Capes incorporou ao seu portfólio a coordenação do sistema nacional de formação de professores e subsidia ao MEC na elaboração de políticas e atividades de suporte para formação dos docentes em todos os níveis e modalidades de ensino. Portanto, cabe a Capes, em parceria com Estados, municípios e IES que aderirem à proposta, fomentar, instituir a formação inicial e continuada dos profissionais do magistério da educação básica; organizar ações estratégicas a longo prazo para a sua formação em serviço; desenvolver programas de desempenho setorial ou regional com a finalidade de atender a demanda social desses profissionais; monitorar o desempenho dos cursos de licenciaturas nas avaliações realizadas pelo Inep; incentivar e apoiar estudos e averiguações sobre o desenvolvimento e aperfeiçoamento dos conteúdos e das orientações curriculares dos cursos de formação inicial e continuada (GATTI; BARRETO; ANDRÉ , 2011, p. 52).

Para a realização de complexas atividades, foi criado na Capes, o Conselho Técnico Científico da Educação Básica (CTC/EB) e, a Diretoria da Educação Presencial (DEP) que em conjunto com a Diretoria da Educação a Distância formam a complexa estrutura da Capes.

Segundo Freitas (2007, p. 1.217), a CAPES, na coordenação, o FNDE, no financiamento, e o INEP, no processo avaliativo da educação básica, compõem a estrutura dorsal das agências reguladoras no campo da educação. Esse modelo de gestão da formação de professores encontra severas críticas, sobretudo pela presença da Capes coordenando o mesmo.

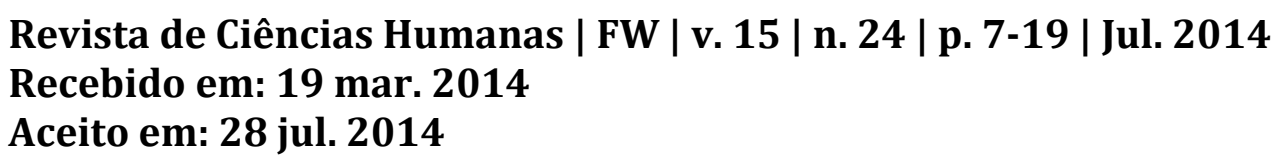

Revista de Ciências Humanas | FW | v. 15 | n. 24 | p. 7-19 | Jul. 2014

Recebido em: 19 mar. 2014

Aceito em: 28 jul. 2014 
Segundo Freitas, a presença da Capes configura a consolidação de um modelo de gestão pautado no produtivismo e competitividade, característica marcante da Capes na condução da pós-graduação no Brasil.

A maneira como o sistema de formação de professores está organizado, fragiliza a carreira docente uma vez que possibilita a figura do mediador do processo educativo, o tutor, sendo que esse, na maioria das vezes, ainda não se encontra em condições adequadas de formação para exercer tal função.

É importante destacar que o tutor é uma figura essencial na educação à distância por desempenhar muitas funções que deveriam ser dos professores. De forma clara, parece que o MEC está anunciando aos professores a sua dispensabilidade no processo educativo.

$\mathrm{Na}$ forma como está organizado todo o processo, o trabalho docente está precarizado e, mais uma vez, a carreira docente está colocada em segundo plano pelos governos.

A política de formação de professores da forma como vem sendo conduzida é uma clara demonstração de que o governo brasileiro tem assumido de forma incondicional os postulados internacionais. Certamente tais postulados não são estabelecidos aleatoriamente, podemos imaginar que a construção de indicadores melhores na educação dos países "emergentes" atende a necessidade de compatibilizar desenvolvimento econômico com avanços na "qualidade" do sistema educacional. Mas o que de fato pretendem os organismos internacionais com a melhora dos indicadores na educação no Brasil? Esta é uma pergunta difícil de responder, mas podemos fazer algumas conjecturas. Além de demonstrar que o desenvolvimento possibilita avanço na qualidade de vida pela melhoria do sistema educacional, há a possibilidade de que esse discurso esconda uma intencionalidade não tão altruísta.

Mais do que nunca o capital necessita ampliar suas margens de produção de maisvalia, e, historicamente isso é feito por meio da exploração do trabalhador. A forma mais eficiente de potencializar essa exploração se dá com a diminuição do valor dos salários e maximização do trabalho. Nesse sentido, a formação de mão de obra para reforçar o exército de reserva é uma alternativa importante. Quanto mais mão de obra disponível no mercado, menores serão os salários, dando assim, uma margem muito pequena de mobilidade aos trabalhadores.

Revista de Ciências Humanas | FW | v. 15 | n. 24 | p. 7-19 | Jul. 2014

Recebido em: 19 mar. 2014

Aceito em: 28 jul. 2014 
Por isso, temos entendido que a política de formação de professores como está configurada, aligeirada, precarizada e produtivista são indicadores do compromisso do governo brasileiro com a expansão do capital. Nesse sentido a afirmação de Marx e Engels (1998, p. 13) de que "O Poder Executivo do Estado moderno não passa de um comitê para gerenciar os assuntos comuns de toda burguesia", continua atual.

Dada às circunstâncias, sob a coordenação da Capes, em 2009, é estabelecida a Política Nacional de Formação de Profissionais do Magistério da Educação Básica, tendo como diretriz central, em período de longo prazo, a formação em serviço. Todavia, para realizar tal tarefa, a Capes precisa criar os Fóruns Estaduais de Apoio à Formação dos Profisssionais da educação, em exigência prevista na "nova" política de formação de professores no Brasil. Como parte importante dessa política, é instituído, ainda em 2009, o Plano Nacional de Formação de Professores da Educação Básica (PARFOR), que tem como objetivo precípuo estabelecer ações e metas para ofertar qualificação a 636.800 mil professores (32\%) em um universo de aproximadamente dois milhões, em 2009, atuando no exercício do magistério sem a formação adequada (GATTI; BARRETO; ANDRÉ, 2011, p. $52)$.

Ainda em 2009, através da Portaria $n^{\circ}$ 318, é realizada a transferência da operacionalização do sistema UAB, à Diretoria de Educação a Distância da Capes. Nesse momento a UAB torna-se representante do sistema nacional da $\mathrm{EaD}$, com o objetivo de padronizar a oferta de cursos e afirmar um modelo que se compõem de professores conteudistas, responsáveis pelo planejamento e preparação dos conteúdos dos cursos, tutores a distância, atuando próximos aos professores dos IESs e, tutores presenciais, atuando junto aos discentes nos polos regionais conforme a Resolução CD/FNDE nº 26/2009.

\title{
CONSIDERAÇÕES FINAIS
}

A política de formação de professores no Brasil, da forma que está concebida, totalmente comprometida com os interesses do capital, inviabiliza qualquer possibilidade de superação desse modelo educacional excludente, competitivo e elitista. Essa organização educacional privilegia a individualidade, categoria particular, atribuindo-lhe o status de

\author{
Revista de Ciências Humanas | FW | v. 15 | n. 24 | p. 7-19 | Jul. 2014 \\ Recebido em: 19 mar. 2014 \\ Aceito em: 28 jul. 2014
}


categoria geral, subsumindo a coletividade, categoria geral, a uma condição fantasmagórica, idealista e utópica.

Com essa forma e conteúdo, a política de formação professores tem um caráter efetivamente produtivista, mecanicista e positivista, sustentado sob os pilares da "inovação" e eficiência economicista, administrada com mão de ferro da Capes.

É uma política que nega a pluralidade cultural, geográfica, política dos diversos grupos constitutivos da sociedade brasileira, e, nega peremptoriamente a luta de classe na mesma, e incentiva a divisão social do trabalho (separação entre trabalho intelectual e manual), nega a natureza ontológica do trabalho na constituição do homem enquanto ser social, portanto, não se preocupa com o processo de precarização do trabalho imposto aos trabalhadoresprofessores formadores e em formação. Portanto, é uma política voltada aos interesses do capital e dos capitalistas, em sintonia com organizações políticas e econômicas nacionais e internacionais, eminentemente liberal/neoliberal, cujo maior valor é a produção de mais valia.

Podemos afirmar que é uma política excludente, pois embora se anuncie democrática, por "permitir" maior acesso ao ensino superior, o faz majoritariamente através da iniciativa privada, sobretudo pela educação a distância, e, mesmo assim, não contempla maioria dos municípios do país. Segundo MEC/INEP em 2011, 3.517 municípios não possuíam nenhum tipo de oferta de formação superior. Através dos dados oficiais podemos contestar essa democratização e afirmar que tal política nunca perdeu seu caráter excludente. Com esse discurso de democratização do ensino, o Estado negligencia as instituições de ensino superior públicas, nega-lhes investimento em pessoal, financeiro e infra-estrutura.

Do ponto de vista da elevação da qualidade na formação de professores no Brasil, a política empreendida pelo Estado nos últimos 17 anos, de governos trabalhistas e/ou sociais democratas, tem sido a mesma, assim como seus resultados. O que há de eficiente nesse processo de formação é a manutenção da vigilância e controle do Estado sobre os futuros professores, os professores em formação e a consolidação da violência simbólica sobre grupos ou classes submetidos a tutela do sistema de ensino. Vale, portanto destacar que as IES não vítimas nesse processo, mas agências de fomento desse modelo de formação de professores; um braço poderoso do Estado na consolidação das políticas públicas de educação.

ABSTRACT: From the Empire (19th century) to the present Republic (21st century), teacher training in Brazil experienced successive failures. Alternate political and economic elites in

Revista de Ciências Humanas | FW | v. 15 | n. 24 | p. 7-19 | Jul. 2014

Recebido em: 19 mar. 2014

Aceito em: 28 jul. 2014 
power, the macro-economic programs, but the problems recur in Brazilian education, not being different in teacher education policy. Teacher education is increasingly in the hands of private enterprise and public universities have surrendered the demands and interests of the market, "producing" well, in series, mediocre teachers. This work aims to present the contradictions and consequences of the policy of teacher education in Brazil. This is an exploratory study of bibliographical.

Keywords: Teacher education. Education. Public education policy.

RESUMEN: Del Imperio (siglo 19) hasta la República actual (siglo 21), la formación de profesores en Brasil experimenta fracasos sucesivos. Se alternan las élites políticas y económicas en el poder, los programas macro-económicos, pero los problemas en la educación brasileña se repiten. La formación de profesores está cada vez más en las manos de la iniciativa privada y, las universidad públicas han se rendido las exigencias e intereses del mercado, "produciendo" así, en serie, profesores medíocres. Este trabajo tiene como objetivo presentar las contradicciones y las consecuencias de la política de formación de profesores en Brasil. Esta es una investigación exploratória de carácter bibliográfico.

Palabras llave: Formación de profesores. Educación. Política pública de educación

\section{REFERÊNCIAS}

BRASIL, EMEC. Instituições de Educação Superior e Cursos Cadastrados. Disponível em: <http://emec.mec.gov.br>. Acesso em: 20/05/2013.

Disponível

MEC/INEP. Resumo Técnico do Censo da Educação Superior de 2011.

<http://download.inep.gov.br/educacao_superior/censo_superior/resumo_tecnico/resumo_tec nico_censo_educacao_superior_2011.pdf>. Acesso em: 20/05/2013.

Beneficiários do Bolsa Família receberão investimentos de $R$ \$ 2 bilhões. Disponível em: <http://www.brasil.gov.br/noticias/arquivos/2013/04/24/beneficiarios-deprograma-social-receberao-investimentos-de-r-2-bilhoes>. 20/05/2013

Decreto $\mathrm{n}^{\circ} 5.622$ de 19 de dezembro de 2005. Regulamenta o art. 80 da Lei $\mathrm{n}^{\circ}$ 9.394, de 20 de dezembro de 1996, que estabelece as diretrizes e bases da educação nacional. Diário oficial da união. Brasília: Casa Civil da Presidência da República, 2005. Disponível em: <http://www.planalto.gov.br/ccivil_03/_ato2004-2006/2005/Decreto/D5622.htm>. Acesso em 17/12/2013.

Lei 10.172, de 09 de janeiro de 2001. Aprova o Plano Nacional de Educação e dá outras providências. Diário oficial da união. Brasília: Casa Civil da Presidência da República, 2001. Disponível em: <http://www.planalto.gov.br/ccivil_03/leis/leis_2001/110172.htm>. Acesso em: 20/05/2013

Revista de Ciências Humanas | FW | v. 15 | n. 24 | p. 7-19 | Jul. 2014

Recebido em: 19 mar. 2014

Aceito em: 28 jul. 2014 
Lei 9.394, de 20 de dezembro de 1996. Estabelece as diretrizes e bases da educação nacional. Diário oficial da união. Brasília: Casa Civil da Presidência da República, 1996. Disponível em: <http://www.planalto.gov.br/ccivil_03/leis/19394.htm>. Acesso em 20/05/2013.

Ministério da Educação. Conselho Nacional de Educação. Resolução CNE/CP n ${ }^{\mathbf{0}} \mathbf{1}$ de 18 de fevereiro de 2002. Institui Diretrizes Curriculares Nacionais para Formação de Professores da Educação Básica, em nível superior, curso de licenciatura, de graduação plena. Portal MEC. Brasília: MEC/CNE/CP 2002. Disponível em: <http://portal.mec.gov.br/cne/arquivos/pdf/rcp01_02.pdf>. Acesso em: 20/05/2012.

. Ministério da Educação. Conselho Nacional de Educação. Resolução CNE/CP no 1 de 15 de maio de 2006. Institui Diretrizes Curriculares Nacionais para Curso de Graduação em Pedagogia, licenciatura. Portal MEC. Brasília: MEC/CNE/CP 2006. Disponível em: <http://portal.mec.gov.br/cne/arquivos/pdf/rcp01_06.pdf>. Acesso em 20/05/2012.

Ministério da Educação. Fundo Nacional de Desenvolvimento da Educação. Resolução CD/FNDE n 26, de 05 de junho de 2009. Estabelece orientações e diretrizes para o pagamento de bolsas de estudo e pesquisa a participantes da preparação e execução dos cursos da UAB. Diário Oficial da União. Brasília: Fnde, 2011. Disponível em: $<$ http://www.uab.capes.gov.br/index.php?option=com_content \&view=article\&id=71\%3Areso lucao-cdfnde-no-26-de-5-de-junho-de-2009\&catid=15\%3Aresolucoes\&Itemid=29>. Acesso em: $17 / 12 / 2013$.

Ministério da Educação. Instituto Nacional de estudos e Pesquisas Educacionais Anísio Teixeira. Sinopse do professor da educação básica. Brasília: MEX/INEP/DEED, 2009.

Ministério da Educação. Portaria $n^{\circ} 2.253$, de 18 de outubro de 2001. Oferta de disciplinas que, em seu todo ou parte, utilizem método não presencial. Diário Oficial da União. Brasília: 2001.2 Disponível em: <http://meclegis.mec.gov.br/documento/view/id/167>. Acesso em: 17/12/2013.

. Ministério da Educação. Portaria n ${ }^{\circ} 4.059$, de 10 de dezembro de 2004. Autoriza a inclusão de disciplinas não presenciais em cursos superiores reconhecidos. Diário Oficial da União. Brasília: $\quad$ MEC, 2009. Disponível em: <http://portal.mec.gov.br/sesu/arquivos/pdf/nova/acs_portaria4059.pdf $>$. Acesso em: $17 / 12 / 2013$.

CAPES. Plano Nacional de Formação de Professores da Educação Básica PARFOR. Consulta em 25/09/2013. Disponível em: <http://www.capes.gov.br/educacaobasica/parfor>. Acesso em: 17/12/2013.

FREITAS, Helena Costa Lopes de. A (nova) polítiva de formação de professores: a prioridade postergada. Educação e Sociedade, v. 28, n. 100, p. 1203-1230, 2007. Disponível em: <http://www.cedes>. Acesso em: 17/12/2013.

Revista de Ciências Humanas | FW | v. 15 | n. 24 | p. 7-19 | Jul. 2014

Recebido em: 19 mar. 2014

Aceito em: 28 jul. 2014 
GATTI, B. A.; BARRETO, E. S. de S. Professores do Brasil: impasses e desafios. Brasília: UNESCO, 2009. 294 p. Disponível em:

<http://unesdoc.unesco.org/images/0018/001846/184682por.pdf>. Acesso em: 25/06/2013.

; NUNES, Marina Muniz R (Orgs.). Formação de professores para o ensino fundamental: estudo de currículos das licenciaturas em pedagogia, língua portuguesa, matemática e ciências biológicas. São Paulo: FCC/DPE, 2009. 160 p. Disponível em:

$<$ http://www.fcc.org.br/biblioteca/publicacoes/textos_fcc/arquivos/1463/arquivoAnexado.pdf $>$. Acesso em: 17/12/2013.

; BARRetTo, E. S. de S.; ANDRÉ, M. D. de A.. Políticas docentes no Brasil: um estado da arte. Brasília: UNESCO, 2011.

LESSA, Sergio, Tonet, Ivo. Proletariado e sujeito revolucionário. São Paulo: Instituto Lukács, 2012. 110 p.

Educação e a teoria marxista da revolução, p. 29-50. In: Trabalho educação e formação humana frente a necessidade histórica. BERTOLDO, Edna; MOREIRA, Luciano Accioly Lemos; JIMENEZ, Susana (Orgs.). São Paulo: Instituto Lukács, 2012. 239 p.

LESSA, Sérgio. Mundo dos Homens: trabalho e ser social. 3. ed. São Paulo: Instituto Lukács, 2012, 254 p.

LUKÁCS, Gyorgy, 1885-1971. Para uma ontologia do ser social. São Paulo: Boitempo, 2012. $434 \mathrm{p}$.

MARX, Karl, ENGELS, Friedrich. O manifesto Comunista. Tradução: Maria Lucia Como. Rio de Janeiro: Paz e Terra, 1998. 67 p.

MARX, Karl. Crítica do Programa de Gotha. Tradução: Rubens Enderle. São Paulo: Boitempo, 2012. 144 p.

MARX, Karl. O capital: critica da economia política. Livro I, v 2. 26. ed. Tradução: Reginaldo Sant'Anna. Rio de Janeiro: Civilização Brasileira, 2008. 966 p.

MARX, Karl. O capital: crítica da economia política. Livro I, v I. 23. ed. Tradução: Reginaldo Sant'Anna, Rio de Janeiro: Civilização Brasileira, 2009. 966 p.

MOACYR, Primitivo. A instrução e as províncias: subsídios para a história da educação no Brasil (1835-1889). v. 2. São Paulo: Editora Nacional, 1937. 614 p. Disponível em: <http://www.brasiliana.com.br/obras/a-instrucao-e-o-imperio-2-vol>. Acesso em: 02/01/2014,

TONET, Ivo. Educação contra o capital. 2. ed. São Paulo: Instituto Lukács, 2012, 93 p.

Revista de Ciências Humanas | FW | v. 15 | n. 24 | p. 7-19 | Jul. 2014

Recebido em: 19 mar. 2014

Aceito em: 28 jul. 2014 